\title{
Transcatheter Trans-aortic Retrograde Approach for the Closure of Perimembranous Ventricular Septal Defects using Cocoon [Amplatzer Duct Occluder I Like] Device - An Initial Experience from a Single Centre
}

Pankaj Jariwala, MD, DNB, DNB, MNAMS, FICPS, FACC*, Kumar Narayanan, MD, DM, Edla Arjun Padma Kumar, MD, DM

Department of Cardiology, Maxcure-Mediciti Hospitals, Hyderabad, Telangana, India

\section{Abstract}

Aims \& Objective: Transcatheter ventricular septal defect (VSD) device closure is usually performed using the antegrade approach [1-3]. A few case series of a retrograde technique using the Amplatzer duct occluder (ADO) II device have been reported [4, 5]. We aimed to assess the feasibility and safety of a retrograde closure technique using an ADO I like device, which is used for the closure of patent ductus arteriosus (PDA).

Methods: Between June 2015 and January 2018, eight consecutive, consenting cases with congenital perimembranous VSDs underwent trans-aortic device closure using an ADO I like device in a single tertiary care center.

Results: The median age was 17.1 years (5-32, SD 17.125 years) with 3 males and 5 females. Mean defect size was $6.6 \mathrm{~mm}(4.5-8.6 \mathrm{~mm}, \mathrm{SD} 6.6125)$, with a median aortic rim of $3.4 \mathrm{~mm}$ (2-5, SD 3.4125). Median Qp/Qs and right ventricular systolic pressure was 1.8 (1.6-2.1, SD 1.825) and $41.3 \mathrm{~mm} \mathrm{Hg}$ (33-50, SD 41.25) respectively. Median fluoroscopy and procedure times were 13.3 (10.6-15.7, SD 13.275) and 23.5 (18.2-27.2, SD 22.722) minutes respectively. The defects were successfully closed with no residual shunt in all 8 patients $(100 \%)$. There was no semilunar or atrioventricular valve leaflet entrapment or regurgitation. There were no instances of acute device dislodgement or Atrioventricular (AV) block. Over a median follow up of $\mathbf{1 8}$ months, all eight patients remained symptom free with no residual shunt or late complications.

Conclusion: In this initial experience, trans-aortic, retrograde VSD device closure using an ADO I like device appears feasible and safe in patients with perimembranous VSDs which a cost effective alternative to routine use of the ADO II device.

Copyright (c) 2019 Science International Corp.

Key Words

Ventricular septal defects - Device closure - Duct occluder

\section{Introduction}

Transcatheter ventricular septal defect (VSD) device closure is a commonly performed procedure to close perimembranous VSDs (PMVSD), especially those that are moderately restrictive without severe pulmonary artery hypertension. Transcatheter clo-

\author{
(c) 2019 Journal of Structural Heart Disease \\ Published by Science International Corp. \\ ISSN 2326-4004 \\ Accessible online at: \\ http://structuralheartdisease.org/
}

* Corresponding Author:

Pankaj Jariwala, MD, DNB, DNB, MNAMS, FICPS, FACC Department of Cardiology

Maxcure-Mediciti Hospitals

Opposite Secretariat, Hyderabad, Telangana, India, 500063

Tel. +91 939317 8738; Fax: +91 402331 2783; E-Mail: pankaj_jariwala@hotmail.com 


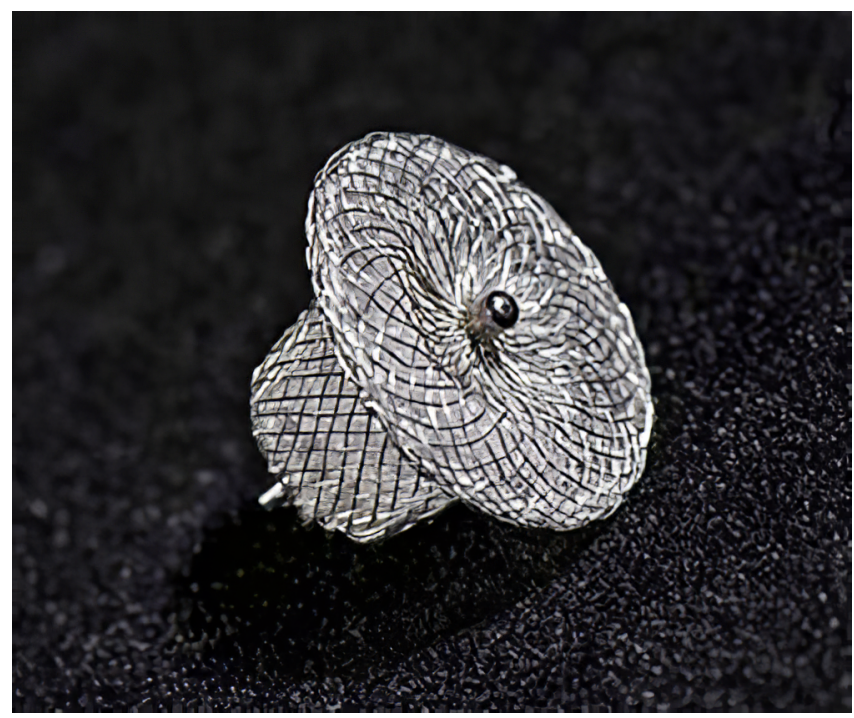

Figure 1. Cocoon device, which is an Amplatzer duct occluder I [ADO I] like device used for the closure of patent ductus occluder. [Reproduced with permission]

sure is preferred wherever possible in view of shorter hospital stay, easier recovery, cost-effectiveness, and cosmetic reasons.

The procedure is commonly done by an antegrade technique via the right ventricle, using an arterio-venous loop. A trans-aortic retrograde technique using Amplatzer membranous or duct occluder (ADO) II has also been described [1]. Though procedure time and radiation exposure is less with the retrograde technique it has certain limitations. It cannot be used in patients with perimembranous VSDs with aortic rim less than $3 \mathrm{~mm}$ [1]. Secondly, the ADO II device is expensive and its routine use, especially in resource-limited settings may not be cost effective. We therefore aimed to assess the feasibility and safety of a retrograde technique for VSD device closure using an indigenously manufactured low cost ADO I like device. We further aimed to demonstrate that this approach could be used irrespective of the adequacy of the aortic rim.

\section{Methods}

\section{Patient population}

This series included eight consecutive patients with perimembranous VSDs who underwent percutaneous VSD device closure by the trans-aortic retro- grade approach using an ADO I like device at a single tertiary care center in South India over a three year period (2015-2018). The hospital institutional review board and ethics committee approved the study. All patients gave informed consent. VSD closure was performed as per standard indications in symptomatic patients, with significant shunt as evidenced by standard clinical (mid-diastolic flow murmur), electrocardiographic (left atrial enlargement, left ventricular hypertrophy) or imaging criteria (Qp/Qs > 1.5 by echocardiography or cardiac catheterization. Perimembranous VSDs with aortic rim less than $5 \mathrm{~mm}$ were also included.

Cases that had significant aortic valve prolapse with aortic insufficiency, defect size $>10 \mathrm{~mm}$, and severe pulmonary hypertension were excluded. The patients underwent clinical and echocardiographic follow-up one week after the procedure and then once every three months for one year.

\section{Description of technique}

Infective endocarditis prophylaxis was administered in all cases. Calculation of VSD diameter and its relation to the aortic valve was determined using trans-thoracic echocardiography (TTE) (Figure 2A \& B) only without performing ventriculography. Following femoral arterial access with a 7 French sheath, the defect was crossed from the left ventricle using an exchangeable 0.035 -inch angulated floppy hydrophilic guide wire (Radio focus, Terumo cooperation, Tokyo, Japan) through either a Judkins right or Amplatz right diagnostic coronary artery catheter (Medtronic, Minnesota, USA) (Figure 3A). The catheter was then advanced over the wire into either the pulmonary artery (PA) or superior vena cava (SVC). The hydrophilic wire exchanged for an Amplatz extra-stiff soft tip wire (Cook Medical Inc. Bloomington, USA). A 7-8 Fr. delivery sheath along with its dilator which used for the closure of patent ductus arteriosus (PDA), was advanced through the defect into the right ventricle (RV) over the Amplatz stiff wire. The sheath was advanced slowly towards the apex of the RV while withdrawing the dilator and was positioned $3-5 \mathrm{~cm}$ beyond the defect (Figure 3B). A device 1 to $2 \mathrm{~mm}$ larger than the measured VSD diameter was pre-loaded on a delivery cable and advanced to the tip of the delivery sheath. The entire system was then withdrawn 


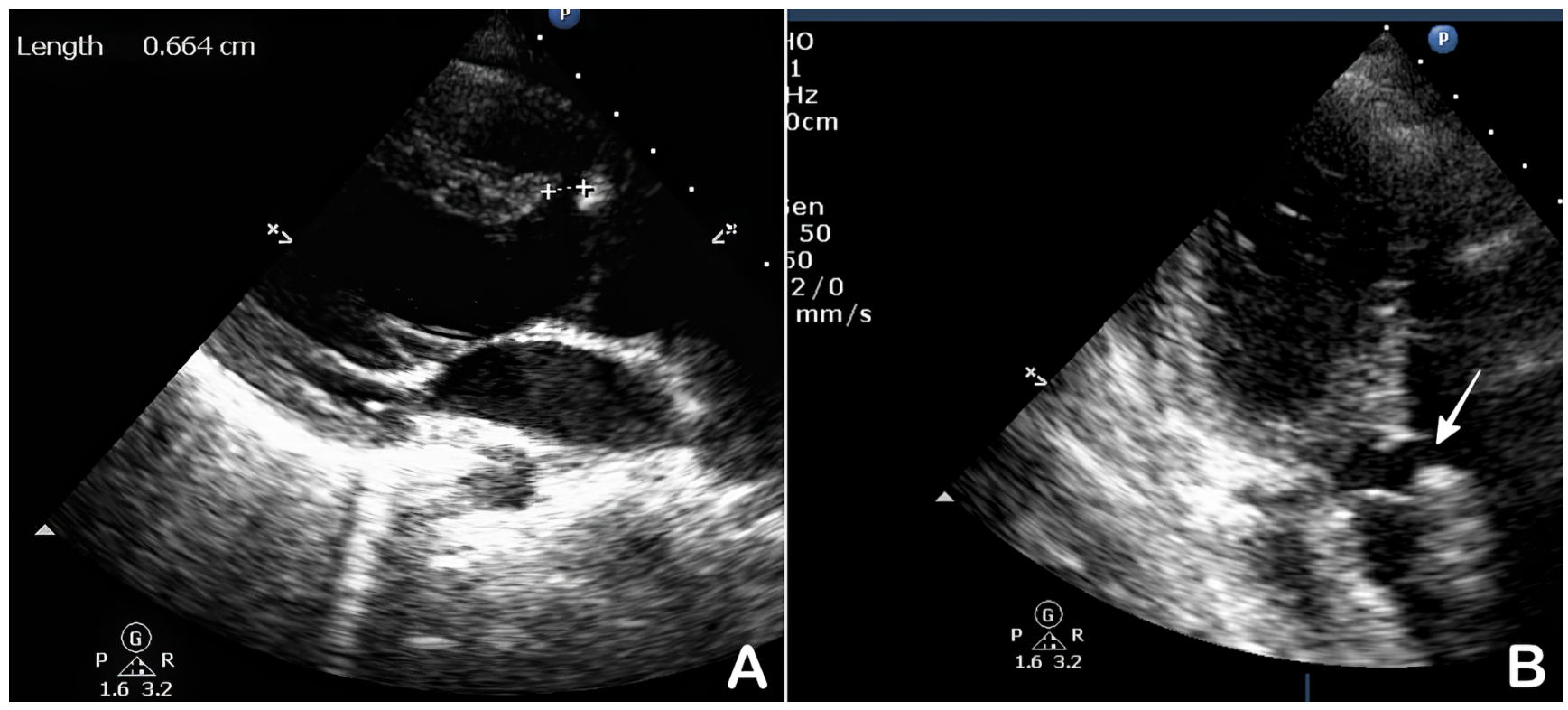

Figure 2. Pre-procedure Trans-thoracic Echocardiography of an illustrated case in Parasternal long axis (Panel A) and apical long axis view (Panel B) demonstrating a perimembranous ventricular septal defect for the measurement of size of the defect.

back towards the VSD under fluoroscopic and transthoracic echocardiographic guidance (Figure 3C). The RV disc was exteriorized 1-2 cm distal to the defect while avoiding entrapment of the chordal elements of the tricuspid valve. The whole system was then further withdrawn till the RV disc was firmly seated on the RV aspect of the defect. Keeping it steady, the sheath alone was then further pulled back to successively deploy the waist and finally the LV disc of the device. Check angiography was performed through the side arm of the delivery sheath by hand injection to confirm device position. TTE was also performed to visualize the placement of the device on the defect, function of the tricuspid, mitral, and aortic valves and

Table 1: Demographic features of the cases, anatomic characteristics of the defects, and data of hemodynamic studies.

\begin{tabular}{|c|c|c|c|c|c|c|c|c|}
\hline Case no & $\begin{array}{l}\text { Patient } \\
\text { Initials }\end{array}$ & Age, years & Gender & $\begin{array}{c}\text { Height/weight/BMI, } \\
\mathrm{Kg} / \mathrm{M} 2\end{array}$ & $\begin{array}{c}\text { Defect } \\
\text { Diameter, } \mathrm{mm}\end{array}$ & $\begin{array}{l}\text { Aortic rim, } \\
\mathrm{mm}\end{array}$ & Qp/Qs & $\begin{array}{l}\text { RVSP, } \\
\mathrm{mmHg}\end{array}$ \\
\hline 1 & BS & 11 & $\mathrm{~F}$ & $34 / 140,17.3$ & 5 & 4 & 1.8 & 38 \\
\hline 2 & PK & 5 & M & $17 / 108,14.6$ & 5.5 & 2.5 & 1.9 & 45 \\
\hline 3 & PB & 32 & M & $78 / 178,24.6$ & 8 & 3.5 & 2.0 & 50 \\
\hline 4 & YP & 25 & M & $68 / 170,23.5$ & 8.6 & 3.8 & 1.6 & 35 \\
\hline 5 & KB & 20 & $\mathrm{~F}$ & $55 / 160,21.5$ & 6.7 & 5 & 1.8 & 44 \\
\hline 6 & PP & 9 & $\mathrm{~F}$ & $25 / 128,15.3$ & 4.5 & 3.6 & 1.75 & 37 \\
\hline 7 & SD & 20 & $\mathrm{~F}$ & $53 / 162,20.2$ & 8 & 2 & 2.1 & 48 \\
\hline 8 & YK & 15 & $\mathrm{~F}$ & $48 / 155,20.0$ & 6.6 & 2.9 & 1.65 & 33 \\
\hline Median & & 17.12 & & $47.25 / 150.1,19.6$ & 6.6 & 3.41 & 1.82 & 41.25 \\
\hline SD & & 17.125 & & $47.25 / 150.125 / 19.625$ & 6.6125 & 3.4125 & 1.825 & 41.25 \\
\hline
\end{tabular}

BMI: Body mass index; Kg: kilograms; M2: square meter; mm: millimeter; Qp/Qs: Shunt fraction; mmHg: millimeter of Mercury; RVSP: right ventricular systolic pressure; M: male; F: female; SD: Standard Deviation. 

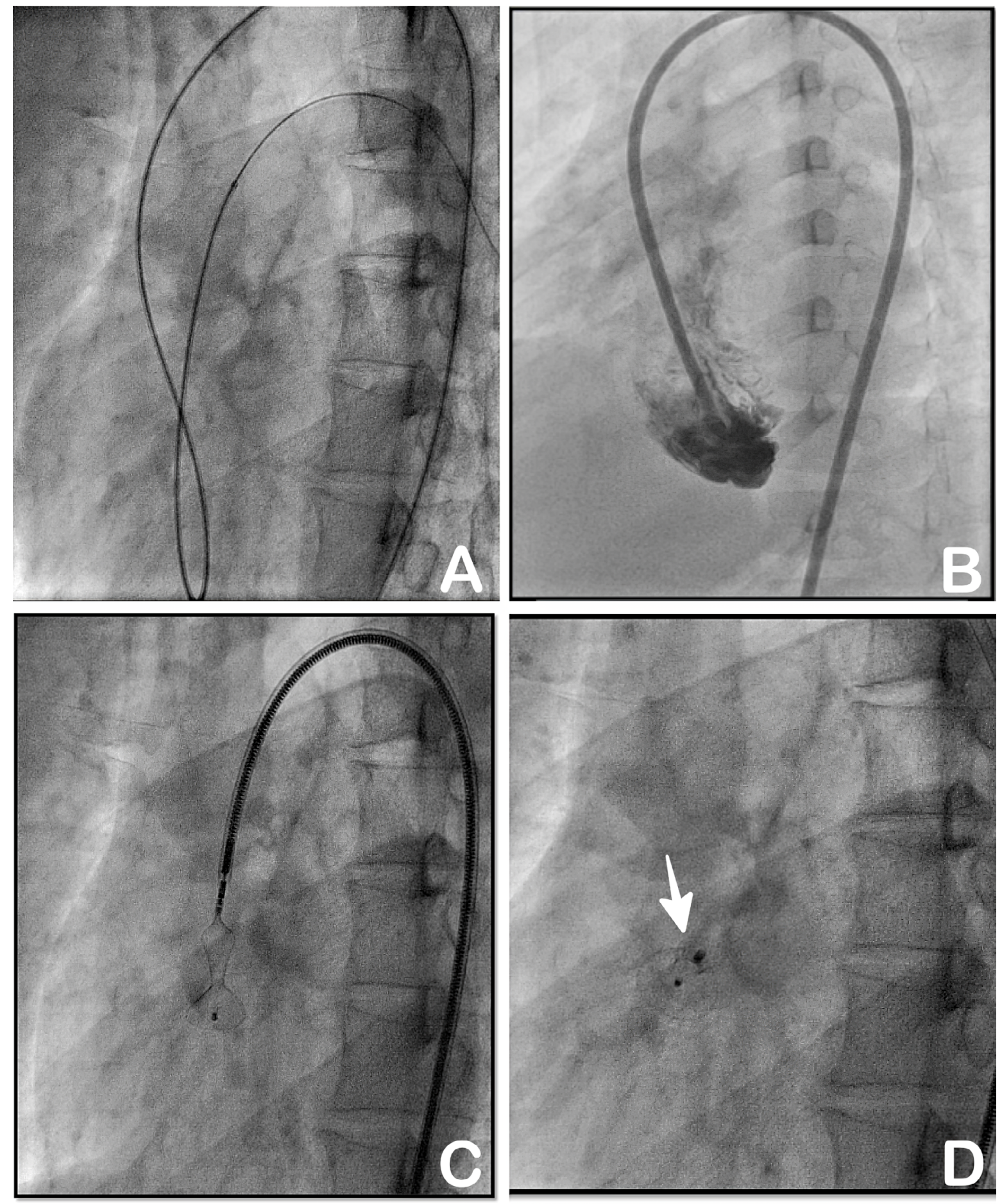

Figure 3. The steps of the procedure (an illustrated case): 0.035 -inch angulated floppy hydrophilic guide wire, Terumo from the left ventricle through a Judkins right diagnostic catheter was advanced to the pulmonary artery exchanged with an Amplatz extra-stiff wire. Panel A. 7Fr. long delivery sheath of PDA was advanced through the defect into the right ventricle over the rigid wire which was advanced further to the apex of the right ventricle. It was confirmed by hand injection of contrast through the side arm of the delivery sheath. Panel B. Complete system was withdrawn with the exteriorized RV disc to be deployed on the right ventricular side and waist of the device across the defect. Panel $C$. The device was released after confirmation of its position across the defect (Panel D) by trans-thoracic ecocardiography which also rules out aortic regurgitation. 

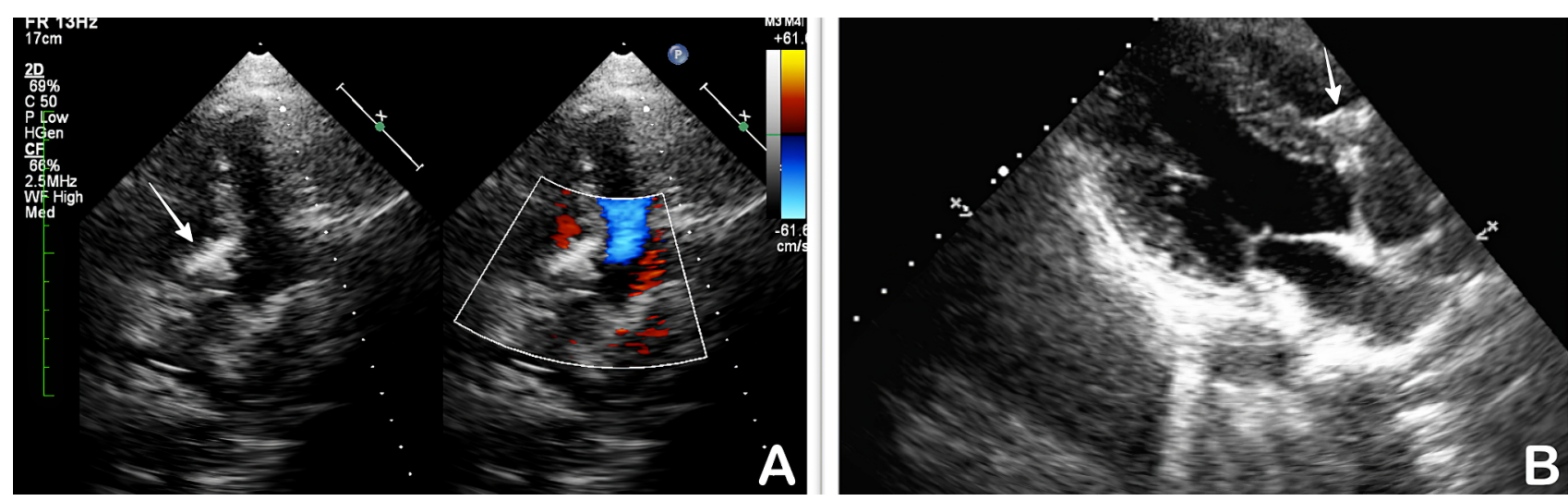

Figure 4. Post-procedure Trans-thoracic Echocardiography (an illustrated case) in four chamber view (color compare, Panel A) and parasternal long axis view (Panel B) after the procedure which demonstrated the secure, well aligned position of the ADO I like device across the defect without any residual shunt and aortic, mitral or tricuspid regurgitations. The white solid arrow showing right ventricular disc and no disc on left ventrcular side (White asterisk).

any residual shunt prior to finally releasing the device (Figure 3D) All patients were administered dual antiplatelet therapy with acetylsalicylic acid $3-5 \mathrm{mg} / \mathrm{kg} /$ day and clopidogrel $1-2 \mathrm{mg} / \mathrm{Kg} /$ day for the duration of six months post device closure.

Close follow-up was done on $10^{\text {th }}$ day post-discharge using Clinical examination and TTE. (Figure 4) Thereafter, patients were followed every 3 months for the period of one year or earlier if patients develop any symptoms in the form of breathlessness, giddiness or syncope. After one year, follow - ups were advised either symptom driven or every 4 to 6 months.

\section{Occluder devices}

We used the 'Cocoon' PDA device [manufactured by Vascular Innvovations Co. Ltd. Nonthaburi,Thailand \& marketed by Vascular Concepts, Bangalore, India] which is very similar to the Amplatzer duct occluder I (ADO I) in terms of design and implantation technique (Figure 1).

\section{Results}

Between June 2015 and January 2018, eight patients underwent VSD device closure using the technique and device described above. Demographic and clinical characteristics of the cases are summarized in Table 1. The median age was 17.1 years (range 5-32 years) with 3 males and 5 females. All patients had perimembranous ventricular septal defects. Mean de- fect size was $6.6 \mathrm{~mm}(4.5-8.6 \mathrm{~mm})$, with a median aortic rim of $3.4 \mathrm{~mm}$ (range $2-5 \mathrm{~mm}$ ). Aortic rims were < $5 \mathrm{~mm}$ in all cases except one. Median Qp/Qs and right ventricular systolic pressure were 1.8 (range: 1.6-2.1) and $41.3 \mathrm{~mm} \mathrm{Hg}$ (range: $33-50 \mathrm{~mm} \mathrm{Hg}$ ) respectively.

All patients underwent successful VSD device closure using the retrograde approach. The procedural details are presented in Table 2. Median fluoroscopy and procedure times were 13.3 (10.6-15.7) and 23.5 (18.2-27.2) minutes respectively. Device sizes ranged from $4 / 6$ to $10 / 12 \mathrm{~mm}$ and $10 / 12 \mathrm{~mm}$ was the maximum size used in this series. One patient had minimal residual shunt and the rest had no residual shunt acutely after device deployment. There was no impingement on either the tricuspid or aortic valves from the device with no instances of valvular regurgitation. Additionally no patient developed hemolytic anemia or jaundice in the post procedure period.

All Patients were discharged 24 hours after the procedure. No acute device dislodgements or AV block were encountered. No other acute complications occurred in the immediate post procedural period and all patients made an uneventful recovery.

Patients were followed for a median of 18 (12 - 28) months during which all stayed asymptomatic with good effort tolerance. There was no residual shunt or late dislodgement of the device by echocardiography in any case. No patient developed delayed conduction system disturbance or AV block. 
Table 2: Procedural details of Trans-aortic retrograde VSD closure using ADO I like device.

\begin{tabular}{|c|c|c|c|c|c|}
\hline Case no & Occluder size, $\mathrm{mm}$ & Delivery system, Fr & Residual shunt & $\begin{array}{l}\text { Fluoroscopy time, } \\
\text { min. }\end{array}$ & $\begin{array}{l}\text { Procedure time, } \\
\text { min. }\end{array}$ \\
\hline 1 & $6 / 8$ & 7 & No & 15.6 & 25.6 \\
\hline 2 & $6 / 8$ & 7 & No & 15.7 & 27.2 \\
\hline 3 & $10 / 12$ & 8 & No & 13.2 & 25.0 \\
\hline 4 & $10 / 12$ & 8 & Minimal & 14.4 & 24.7 \\
\hline 5 & $8 / 10$ & 7 & No & 11.1 & 19.4 \\
\hline 6 & $4 / 6$ & 7 & No & 12.2 & 18.2 \\
\hline 7 & $10 / 12$ & 8 & No & 13.4 & 22.3 \\
\hline 8 & $6 / 8$ & 7 & No & 10.6 & 18.6 \\
\hline Median & & & & 13.3 & 23.5 \\
\hline SD & & & & 13.275 & 22.722 \\
\hline
\end{tabular}

mm: millimeter; Fr: French size; min: Minutes; SD: Standard Deviation

\section{Discussion}

To the best of our knowledge, this is the first reported case series in literature using a combination of retrograde VSD device closure technique and ADO I like device. Though the retrograde approach has been described before using the ADO II device [1-3], there are some limitations in cases with aortic rim less than $5 \mathrm{~mm}$ and more procedure time and radiation exposure. The ADO II device is also relatively expensive to use in resource limited contexts such as the Indian setting. Koneti et al. reported the fluoroscopy time of 14 minutes in their series where trans-arterial retrograde technique was done using an ADO II device. [4] In our series, fluroscopy time was 13.3 minutes. As our experience grew, there was further reduction of fluroscopy time from 15.7 to 10.6 minutes.

In this series, we used an ADO I like device - 'Cocoon Device" [manufactured by Vascular Innvovations Co. Ltd. Nonthaburi, Thailand \& marketed by Vascular Concepts, Bangalore, India] for the first time using a trans-aortic retrograde technique. We were able to use this device in all cases irrespective of aortic rim size. Another advantage of using ADO I like device is that it has a low profile with small retention disc on the right ventricular side and no disc on the left ventricular side which lowers the risk of encroachment on vital cardiac structures. We also used 7/8 Fr
PDA delivery systems, which helped in achieving better stability for delivery of device without any twist or kink across the interventricular septum. Koneti et al., on the other hand, used the right coronary guide catheter for the delivery of retrograde devices. They encountered tortuosity of the catheter while across the septum which was overcome by using an extra support coronary guide wire (buddy wire) [1].

Porstmann et al. did the first trans-catheter closure of Patent Ductus Arteriosus (PDA) in 1967. Later, Lock et al. reported transcatheter closure of VSD using 'Rashkind double umbrella' device in 1988 [5]. After the introduction of the Amplatzer device in 1999, the closure of muscular VSDs using the Amplatzer muscular VSD occluder (MVSDO) was published in 2002. Though transcatheter closure of muscular VSDs, was a better option than surgical closure, significant incidence of atrioventricular block varying from to 3-20\% was seen [6]. Despite the development of the dedicated Amplatzer Perimembranous VSD Occluder (PMVSDO) for the closure of perimembranous VSDs, a occurrence of AVB was a concern $[7,8]$. The tranvenous antegrade technique had more radiation exposure and cumbersome procedure. The trans-arterial retrograde technique, initially using the Amplatzer symmetrical muscular VSD device $[9,10]$ and subsequently the $A D O$ II device to minimize the risk of atrioventricular block (AVB) and tricuspid valve en- 
trapment with possible tricuspid regurgitation during follow-up, got more attention $[2,4]$. The advantage of this approach is that it is also useful in patients with venous anomalies, such as interrupted inferior vena cava [11]. It has been reported that the trans-aortic approach causes a lower incidence of AVB than the antegrade approach [9, 12].

ADO I or its chinese counterparts were used in a few case reports by antegrade approach for the closure of residual post-surgical VSDs $[13,14]$ and for the closure of multi-perforated perimembranous VSD with aneurysm [15]. Recently, Nguyen et al. published a multicenter case series of antegrade transvenous closure of PMVSD using ADO I with 95\% success rate and with complications in $1.7 \%$ of cases. They had embolization of device in $1 \%$ of cases and AVB in $0.7 \%$ of cases [16].

The risk of embolization is inherant complication of any device closure but in our case, the non-presence of disc on the LV side doesnot increase it further. Basically, device sits there as it fits snuggly and the LV pressure cannot push the device as the LV contracts circumferentially in systole by rotation and torsion [17]. In our small case series, there were no embolization and also no evidence of tricuspid regurgitation. One case had minimal residual shunt which resolved completely at the 1-month follow-up.

\section{Study limitations}

Our study had a small number of cases, and should be considered an initial feasibility study. More long- term data with larger number of patients will be needed to draw more definitive conclusions. In this initial series, we did not attempt to close larger defect sizes, patients $<3$ years of age or those with severe reversible pulmonary artery hypertension; hence our findings may not be applicable to these subsets. However the data from this early study appears promising and should prompt further evaluation in a wider spectrum of patients.

\section{Conclusion}

In this initial experience, retrograde trans-arterial closure of VSD using an ADO-I like device appears feasible and relatively more cost-effective. It can help further reduce radiation exposure and can be potentially applied in all cases even with deficient aortic rim. Further studies are required to document its efficacy, safety and long-term results in a larger number of patients.

\section{Conflict of Interest}

The authors have no conflict of interest relevant to this publication.

Comment on this Article or Ask a Question

\section{References}

1. Koneti NR, Sreeram N, Penumatsa RR, Arramraj SK, Karunakar V, Trieschmann U. Transcatheter Retrograde Closure of Perimembranous Ventricular Septal Defects in Children With the Amplatzer Duct Occluder II Device. J Am Coll Cardiol. 2012;60:24212422. DOI: 10.1016/j.jacc.2012.08.1004

2. Suligoj B, Cernic N, Zorc M, Noc M, Kar S. Retrograde transcatheter closure of ventricular septal defect with Amplatzer Duct Occluder II. Postep w Kardiol Interwencyjnej. 2016;12:177-178. DOI: 10.5114/ aic.2016.59371

3. Pekel N, Ercan E, Özpelit ME, Özyurtlu F, Yılmaz A, Topaloğlu C, et al. Directly ventricular septal defect closure without using arteriovenous wire loop: Our adult case series using transarterial retrograde approach. Anatol J Cardiol. 2017;461-468. DOI: 10.14744/AnatolJCardiol.2017.7507

4. Koneti NR, Penumatsa RR, Kanchi V, Arramraj SK, S J, Bhupathiraju S. Retrograde transcatheter closure of ventricular septal defects in children using the Amplatzer Duct Occluder II. Catheter Cardiovasc Interv. 2011;77:252-259. DOI: 10.1002/ccd.22675

5. Lock JE, Block PC, McKay RG, Baim DS, Keane JF. Transcatheter closure of ventricular septal defects. Circulation 1988;78:361368. DOI: 10.1161/01.CIR.78.2.361

6. Thanopoulos BD, Tsaousis GS, Konstadopoulou GN, Zarayelyan AG. Transcatheter closure of muscular ventricular septal defects with the Amplatzer ventricular septal defect occluder: Initial clinical applications in children. J Am Coll Cardiol. 1999;33:1395-1399. DOI: 10.1016/S07351097(99)00011-X

7. Szkutnik M, Kusa J, Białkowski J. Percutaneous closure of perimembranous ventricular septal defects with Amplatzer occluders--a single centre experience. Kardiol Pol. 2008;66:941-949. PMID: 18924021

8. Carminati $M$, Butera $G$, Chessa $M$, Drago $M$, Negura D, Piazza L. Transcatheter closure of congenital ventricular septal defect with Amplatzer septal occluders. Am J Cardiol. 2005;96:52L-58L. DOI: 10.1016/j. amjcard.2005.09.068

9. Muthusamy K. Retrograde closure of perimembranous ventricular septal defect us- 
ing muscular ventricular septal occluder: a single-center experience of a novel technique. Pediatr Cardiol. 2015;36:106-110. DOI: 10.1007/s00246-014-0971-x

10. Szkutnik M, Qureshi SA, Kusa J, Rosenthal E, Bialkowski J. Use of the Amplatzer muscular ventricular septal defect occluder for closure of perimembranous ventricular septal defects. Heart. 2007;93:355-358. DOI: $10.1136 /$ hrt.2006.096321

11. El-sisi A, Ali S. Retrograde Percutaneous Closure of a Perimemberanous Ventricular Septal Defect with an Occluder Device in a Child with Interrupted Inferior Vena Cava. J Struct Hear Dis. 2017;3:111-114. DOI: 10.12945/j.jshd.2017.014.16

12. Goy J-J, Ruchat P, Stolt V, Schlueter L, Berger A. Percutaneous closure of ventricular septal defect following aortic valve replacement. Kardiovaskulare Medizin. 2014;17:266-268. DOI: 10.4414/ cvm.2014.00270
13. Djer MM, Idris NS, Alwi I, Wijaya IP. Transcatheter closure of post-operative residual ventricular septal defect using a patent ductus arteriosus closure device in an adult: a case report. Acta Med Indones. 2014;46:233-237. PMID: 25348186

14. Vaidyanathan B, Kannan BR, Kumar RK. Device closure of residual ventricular septal defect after repair of tetralogy of Fallot using the amplatzer duct occluder. Indian Heart J. 2005;57:164-166. PMID: 16013358

15. Wierzyk A, Szkutnik M, Fiszer R, Banaszak P, Pawlak S, Biakowski J. Transcatheter closure of ventricular septal defects with nitinol wire occluders of type patent ductus arteriosus. Postep w Kardiol Interwencyjnej. 2014;10:21-25. DOI: 10.5114/ pwki.2014.41462

16. Nguyen $\mathrm{HL}$, Phan $\mathrm{QT}$, Doan DD, Dinh LH, Tran HB, Sharmin S, et al. Percutaneous closure of perimembranous ventricular septal defect using patent ductus arteriosus oc- cluders. PLoS One. 2018;13:e0206535. DOI: 10.1371/journal.pone.0206535

17. Nakatani S. Left Ventricular Rotation and Twist: Why Should We Learn? J Cardiovasc Ultrasound. 2011;19:1-6. DOI: 10.4250/ jcu.2011.19.1.1

Cite this article as: Jariwala $P$, Narayanan K, Kumar EAP. Transcatheter Trans-aortic Retrograde Approach for the Closure of Perimembranous Ventricular Septal Defects using Cocoon [Amplatzer Duct occluder I Like] device - An Initial Experience from a Single Centre. Structural Heart Disease. 2019;5(5):221228. DOI: https://doi.org/10.12945/j. jshd.2019.002.19 